\title{
Current status of bioartificial kidney
}

\author{
Sung Joon Shin \\ Department of Nephrology, Dongguk University Ilsan Hospital, Dongguk University, Seoul, South Korea \\ Email:wizdocrc@gmail.com
}

Received 27 December 2013; revised 31 January 2014; accepted 8 February 2014

Copyright (C) 2014 Sung Joon Shin. This is an open access article distributed under the Creative Commons Attribution License, which permits unrestricted use, distribution, and reproduction in any medium, provided the original work is properly cited. In accordance of the Creative Commons Attribution License all Copyrights (C) 2014 are reserved for SCIRP and the owner of the intellectual property Sung Joon Shin. All Copyright (C) 2014 are guarded by law and by SCIRP as a guardian.

\section{ABSTRACT}

Current dialysis systems are not perfect considering the low efficacy and cumbersome process of actual practice. To overcome these shortcomings, bioartificial kidneys using renal tubule cells and wearable dialysis are promising ESRD treatments available in the near future. Toward clinical application, however, there are so many obstacles for commercial use of them. In this review, current status of bioartificial kidneys such as the renal tubule cell assist device (RAD) and wearable dialysis devices is presented with the comparison to show the advantages and disadvantages.

\section{KEYWORDS}

\section{Bioartificial Kidney; Renal Tubule Cell Assist Device; Wearable Dialysis}

\section{INTRODUCTION}

Worldwide, about two million people including 600,000 Americans have been suffering end stage renal disease. Although the incidence of ESRD patients is increasing by 5 percent a year, therapeutic options and methods in the ESRD have not been changed significantly. Which do you think will be the best ESRD treatment in 2025? According to a 2007 report of the dialysis opinion survey, which has been conducted at major nephrology and dialysis congresses since 1992, stem cell therapy was the first (2541/6595, 39 percent) and the second was the miniaturized, wearable, and bionic dialysis (1824/6595, 28 percent). Only 597 among 6595 respondents (nine percent) said that dialysis system would be similar to what we have today.

At this moment, bioartificial kidney and wearable, miniaturized dialysis are the promising ESRD treatments available in the near future as we had expected [1].

\section{BIOARTIFICIAL KIDNEY AND WEARABLE DIALYSIS DEVICE}

\subsection{Bioartificial Kidney Using Renal Tubule Cells}

Primary human renal tubule cells can be isolated and show differentiated absorptive, metabolic, and endocrine functions of the natural kidneys. The renal tubule cell assist device (RAD) is an extracorporeal device with a standard hemofiltration cartridge covered by nonautologous human renal tubular cells along the inner surface (Figure 1). This addition of renal tubule cell therapy to CVVH treatment improved day 28 mortality (RAD vs. conventional CRRT, $33 \%$ vs. $61 \%$ ) and was associated with more rapid recovery of kidney function in ICU patients with AKI in the randomized, multicenter trial [2]. Moreover, this bioengineered bioartificial device using renal tubule cells showed metabolic activity and influenced systemic leukocyte activation and the balance of inflammatory cytokines, suggesting the bioengineered device may be beneficial to patients with acute kidney injury and multiorgan failure [3].

Stem cells play significant roles in kidney repair in

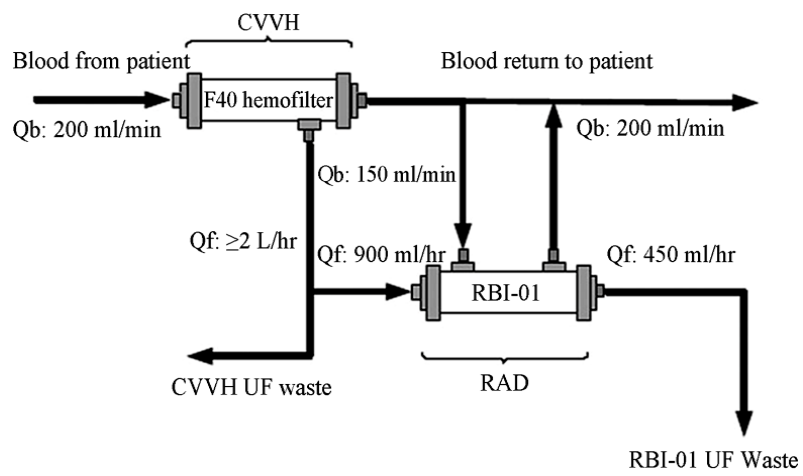

Figure 1. Schematic circuit for extracorporeal perfusion system using the hemofilter and the renal tubule cell assist device (from Tumlin, J. et al. J Am Soc Nephrol. 2008). 
various pathological conditions. Stem cells have a capacity of self-renewal and can divide to specialized and differentiated cell types. There are so many obstacles for commercial use of stem cells toward clinical application [3]. For example, bioengineered cell system should be capable of passing the various regulatory testing and suitable for mass production. Besides that, government-related organization such as FDA or EMA should approve human clinical trial testing. Recently, methodology about the differentiation of human embryonic stem cells into functional renal tubular cells has been described [4], and it will be helpful to accelerate the development of bioartificial kidney.

\subsection{Wearable Dialysis System}

Current dialysis systems are far from perfect considering that the efficacy is at least about 10 percent of that of a normal functioning human kidney. It is easy to anticipate the beneficial effect of more frequent and longer dialysis sessions on the improvement of cardiovascular risk factors and short-term outcomes [5,6], even though it is rarely possible in real clinical situation. To overcome shortcomings of today's dialysis system via technical breakthroughs, wearable dialysis devices have been developed and presented $[7,8]$. Theoretically, wearable dialysis devices should function without cessation similar to native human kidney but, all of them show strengths and weaknesses [1] (Table 1).

\subsubsection{Wearable Hemodialysis System}

The key of wearable hemodialysis system is mini-pump that can generate continuous countercurrent blood and dialysate flows and efficient battery which should be very small, lightweight and lasting for at least 24 hours. Moreover, for the safe of patients, the problems related to air bubbles and blood clotting should be considered. Vascular access is essential element of hemodialysis system.
Davenport A, Gura V, and Ronco C reported most published papers about wearable hemodialysis device [9-12] (Figure 2). In 2007, they presented wearable, continuous ultrafiltration machine [12]. Even though the device, wearable artificial kidney (WAK), used a commercially available dialyzer with a standard 9 volts battery, it was a little bit heavier as much as about $5 \mathrm{~kg}$. Functionally, the device operated with mean blood flow 58.6 (SD 11.7) $\mathrm{mL} / \mathrm{min}$, and a dialysate flow of $47.1(7.8) \mathrm{mL} / \mathrm{min}$. The mean plasma urea clearance rate was 22.7 (5.2) $\mathrm{mL} / \mathrm{min}$ and the mean plasma creatinine clearance rate was 20.7 (4.8) $\mathrm{mL} / \mathrm{min}$. Clinical experiment in eight ESRD patients showed no significant cardiovascular changes and no adverse changes in serum electrolytes or acid-base balance. The technological breakthrough in WAK was pulsatile pump and dialysate regeneration with the advantage of light system and low power. The shortcoming of WAK was variation of dialysate composition. In 2008, the first human study was reported using a wearable hemofilter for a slow continuous ambulatory ultrafiltration [11]. In 2011, pilot study of wearable hemodialysis device with a sorbent-based regeneration dialysate system demonstrated the safety with a similar clearance to CRRT used in the intensive-care unit [9].

\subsubsection{Wearable Peritoneal Dialysis System}

The Vicenza wearable artificial kidney for peritoneal dialysis (ViWAK PD) is a prototype of wearable peritoneal dialysis device (Figure 3). First article of ViWAK PD was reported in 2007 [13]. The ViWAK system consists of a double lumen peritoneal catheter; a dialysate outflow line; a miniaturized rotary pump; a circuit for dialysate regeneration featuring a water proof container with cartridges connected in parallel with a mixture of activated carbon andpolystyrenic resins; a filter for deaeration and micro-biological safety; a dialysate inflow line; a palm computer as a remote control [14]. The creatinine and beta 2-microglobulin clearance was in the range of

Table 1. Comparison of various devices for wearable artificial kidney (modified from 1, 7).

\begin{tabular}{|c|c|c|c|c|c|}
\hline Device & Therapeutic modality & Technological breakthrough & Advantages & Disadvantages & Current status \\
\hline RAD & HFR & $\begin{array}{l}\text { Nanostructured hemofilter } \\
\text { with cell function }\end{array}$ & Metabolic function & $\begin{array}{l}\text { Low surface area } \\
\text { difficult to replace }\end{array}$ & Under development \\
\hline WAK & Hemodialysis & $\begin{array}{l}\text { Pulsatile pump dialysate } \\
\text { regeneration }\end{array}$ & $\begin{array}{l}\text { Low power light weight } \\
\text { small dialysate volume }\end{array}$ & $\begin{array}{l}\text { Variation of dialysate } \\
\text { composition and } \mathrm{pH}\end{array}$ & Clinical trial \\
\hline ViWAK & Peritoneal dialysis & $\begin{array}{l}\text { Remote control double } \\
\text { lumen PD catheter }\end{array}$ & $\begin{array}{l}\text { Less dialysate volume } \\
\text { less protein loss }\end{array}$ & $\begin{array}{l}\text { Variation of dialysate composition } \\
\text { and pH glucose infusion lack of } \\
\text { small molecule removal }\end{array}$ & Prototype \\
\hline AWAK & Peritoneal dialysis & $\begin{array}{l}\text { Dialysate regeneration } \\
\text { protein regeneration }\end{array}$ & $\begin{array}{l}\text { Less dialysate volume } \\
\text { less protein loss }\end{array}$ & $\begin{array}{l}\text { Variation of dialysate composition } \\
\text { and pH glucose infusion }\end{array}$ & Before clinical trial \\
\hline
\end{tabular}

AWAK: Automated wearable artificial kidney, HFR: Hemodiafiltration with endogenous reinfusion, RAD: Renal tubule cell assist device, ViWAK: Vicenza wearable artificial kidney for peritoneal dialysis, WAK: Wearable artificial kidney. 


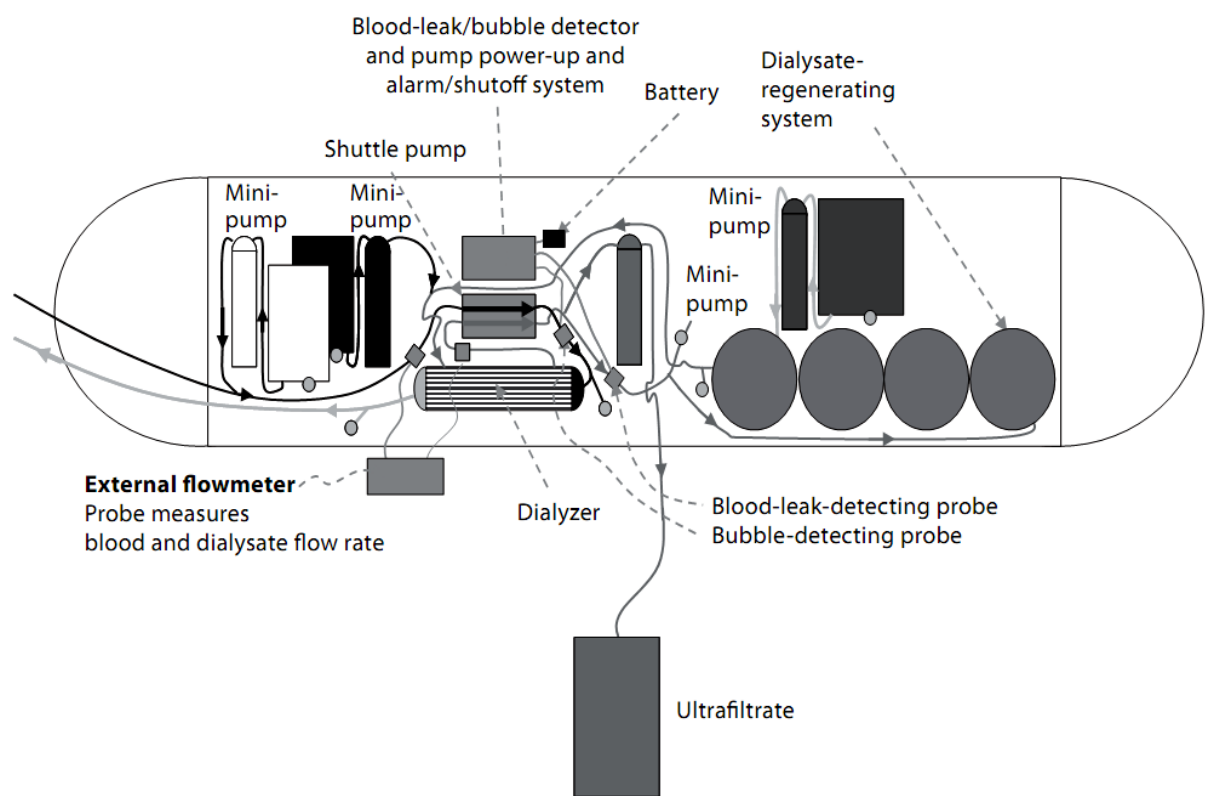

Figure 2. Circuit design of the wearable artificial kidney v 1.2 demonstrating 4 minipumps to control infusion of heparin, bicarbonate and electrolytes for regeneration of dialysate and ultrafiltration (US Patent No. 6,960,179) (from Ronco, C. and Rosner, M.H. Contrib Nephrol. 2011).

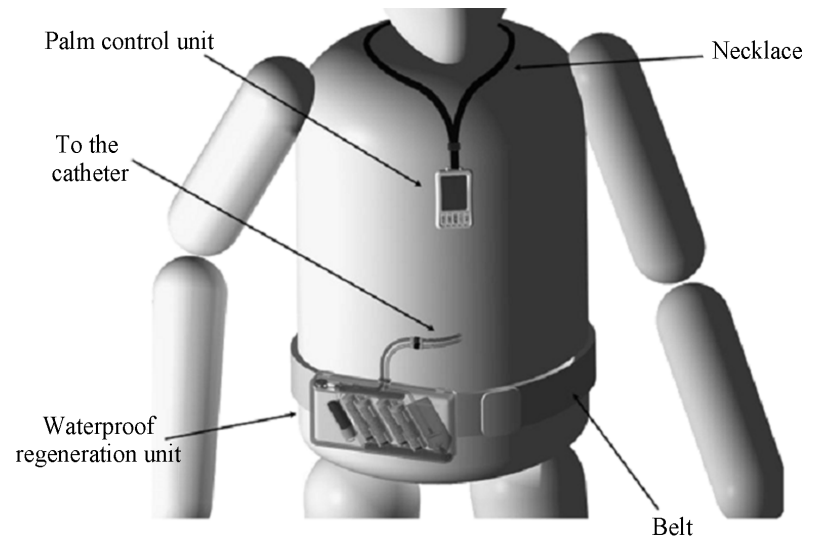

Figure 3. Schematic design of a wearable peritoneal dialysis system (from Davenport, A., et al. Hemodialysis International 2010).

15 - 16 liters/day, corresponding to a weekly clearance of 100 - 110 liters. The net solute clearance was 11.2 liters. It was a promising result that showed possibility as an alternative option to APD and CAPD. For commercial use, however, some weaknesses of ViWAK should be made up by the applying of an injection port, a system to decrease fibrin delivery to the sorbent and increase removal of various size of uremic toxins. Another wearable peritoneal dialysis system is automated wearable artificial kidney (AWAK) [15]. AWAK required no extracorporeal circulation and was designed to continuously regenerate and reuse the dialysate. The disadvantages of AWAK were related to the variation of dialysate composition and glucose infusion.

\section{DISCUSSION}

Wearable artificial kidneys are feasible in modern technology. Even though technical breakthrough and advantages, several problems should be considered [7,16] (Table 1). First, will it be convenient all day long, especially during sleeping time? Are there no problems in device weight and operation time without recharging the batteries? Second, is method for blood access reliable and safe? Third, will it be safe in emergent situation such as the risk of mitigation and technical system error? Forth, is there no interference with the new technical device electromagnetically? To solve the problems, a collaborative effort in various fields will be needed not only in medicine but also in technology.

Although studies about cell therapy and wearable devices have not been conducted for quite a long-term period, it is promising that these new therapies will be available as options in the near future. Do you remember the first commercial models of cellular phone in 1980s, which were very big, ugly-looking and expensive? After three decades, the designs and functions of cellular phones have been dramatically changed. Considering that, it is not a daydream that new therapeutic options such as bioengineered artificial kidney and wearable dialysis devices for ESRD patients will be applied in the routine clinical practice in nephrology area.

\section{REFERENCES}

[1] Kim, J.C. and Ronco, C. (2013) Personal daily dialysis: 
The evolution of the artificial kidney. Blood Purification, 36, 47-51. http://dx.doi.org/10.1159/000350586

[2] Tumlin, J., Wali, R., Williams, W., et al. (2008) Efficacy and safety of renal tubule cell therapy for acute renal failure. Journal of the American Society of Nephrology, 19, 1034-1040. http://dx.doi.org/10.1681/ASN.2007080895

[3] Buffington, D.A., Westover, A.J., Johnston, K.A. and Humes, H.D. (2013) The bioartificial kidney. Translational Research: The Journal of Laboratory and Clinical Medicine. http://dx.doi.org/10.1016/j.trsl.2013.10.006

[4] Narayanan, K., Schumacher, K.M., Tasnim, F. and Kandasamy, K., et al. (2013) Human embryonic stem cells differentiate into functional renal proximal tubular-like cells. Kidney International, 83, 593-603. http://dx.doi.org/10.1038/ki.2012.442

[5] Mehrotra, R. and Himmelfarb, J. (2013) Dialysis in 2012: Could longer and more frequent haemodialysis improve outcomes? Nature Reviews. Nephrology, 9, 74-75. http://dx.doi.org/10.1038/nrneph.2012.287

[6] Wheeler, D.C. and Caplin, B. (2012) New observational data demonstrate that mortality is lower in patients receiving more frequent dialysis. Journal of the American Society of Nephrology, 23, 770-773. http://dx.doi.org/10.1681/ASN.2012030311

[7] Kim, J.C., Garzotto, F., Nalesso, F. and Cruz, D., et al. (2011) A wearable artificial kidney: Technical requirements and potential solutions. Expert Review of Medical Devices, 8, 567-579. http://dx.doi.org/10.1586/erd.11.33

[8] Kim, J.C. and Ronco, C. (2011) Current technological approaches for a wearable artificial kidney. Contributions to Nephrology, 171, 231-236.

\section{http://dx.doi.org/10.1159/000327335}

[9] Davenport, A., Ronco, C. and Gura, V. (2011) From wearable ultrafiltration device to wearable artificial kidney. Contributions to Nephrology, 171, 237-242. http://dx.doi.org/10.1159/000327172

[10] Davenport, A., Ronco, C. and Gura, V. (2010) Portable and wearable dialysis: Where are we now? Hemodialysis International. International Symposium on Home Hemodialysis, 14, S22-S26.

[11] Gura, V., Ronco, C., Nalesso, F. and Brendolan, A., et al. (2008) A wearable hemofilter for continuous ambulatory ultrafiltration. Kidney International, 73, 497-502. http://dx.doi.org/10.1038/sj.ki.5002711

[12] Davenport, A., Ronco, C., Gura, V. and Beizai, M., et al. (2007) A wearable haemodialysis device for patients with end-stage renal failure: A pilot study. Lancet, 370, 20052010. http://dx.doi.org/10.1016/S0140-6736(07)61864-9

[13] Ronco, C. and Fecondini, L. (2007) The vicenza wearable artificial kidney for peritoneal dialysis (viwak pd). Blood Purif, 25, 383-388. http://dx.doi.org/10.1159/000107775

[14] Ronco, C., Davenport, A. and Gura, V. (2011) The future of the artificial kidney: Moving towards wearable and miniaturized devices. Nefrologia, 31, 9-16.

[15] Lee, D.B. and Roberts, M. (2008) A peritoneal-based automated wearable artificial kidney. Clinical and Experimental Nephrology, 12, 171-180. http://dx.doi.org/10.1007/s10157-008-0050-9

[16] Polaschegg, H.D. (2011) Wearable dialysis: What is missing? Contributions to Nephrology, 171, 226-230. http://dx.doi.org/10.1159/000327231 